\title{
REPERTORIUM VAN TIJDSCHRIFTLITERATUUR OP HET GEBIED VAN ACCOUNTANCY EN BEDRIJFSHUISHOUDKUNDE
}

Verschïnt maandelijks, behalve in augustus. Samengesteld door de Stichting voor Economisch Onderzoek der Universiteit van Amsterdam

\section{A. ACCOUNTANCY}

\section{HET ACCOUNTANTSBEROEP}

\section{Australia's first accountancy body. The Adelaide Society of Accountants}

P a rker, R. H. - De schrijver geeft een beknopt historisch overzicht van de zich organiserende accountants in Zuid-Australië. In navolging van de ontwikkeling sinds 1850 in het moederland werd de eerste vereniging in 1885 te Adelaide opgericht, een jaar later gevolgd door die te Melbourne. De schrijver geeft in extenso de reactie van de pers weer, waarin wordt opgemerkt dat een dergelijke vereniging zich in twee richtingen kan ontwikkelen: het kan of wel een gezaghebbend orgaan terzake van de taken van de accountant worden of wel degenereren tot niets meer dan een vakvereniging die tracht een ieder uit te sluiten die haar gezag niet wenst te erkennen.

Tussen 1885 en 1928 breidde het arbeidsveld van de leden zich geleidelijk uit, tot in 1928 de vereniging werd opgenomen in het Institute of Chartered Accountants in Australia. De schrijver wijst er tenslotte op dat in de loop der jaren de opleiding voor het beroep van accountant in toenemende mate aandacht heeft gekregen en in de nabije toekomst het universitair niveau steeds dichter zal benaderen.

A II - 2 The Chartered Accountant in Australia, december 1961

E 635.451: E 741.23

\section{Ordening in het accountantswezen}

Udink, B. J. - Tot de essentie van de taak van de accountant behoort het als onafhankelijk deskundige afgeven van een verklaring omtrent de juistheid van de door de beheerders afgelegde verantwoording van hun beheer. De accountant geeft deze verklaring ten behoeve van belanghebbenden af op grond van eigen onderzoek. Het accountantsberoep is niet wettelijk geregeld zodat iedereen zich als accountant kan vestigen. Bovendien is het gebruik geworden dat een zelfstandige boekhouder of belastingdeskundige zich accountant noemt. Het is evenwel van groot belang dat belanghebbenden de voor zijn essentiële taak berekende accountant kunnen herkennen. Tot op zekere hoogte bereikten de accountants dit door zich te organiseren in verenigingen en aan de aankondiging van hun beroep een aanduiding over hun lidmaatschap toe te voegen. Deze toestand heeft echter niet geheel voldaan zodat een wettelijke regeling dringend gewenst is. Een ontwerp tot het invoeren van regelen betreffende het accountantswezen is door de Tweede Kamer aangenomen. De schrijver geeft een korte karakteristiek van dit wetsontwerp dat voorziet in de instelling van een orde van registeraccountants en gaat nader in op de vraag wie registeraccountants kunnen worden.

A. II - 4 Tijdschrift voor Vennootschappen, Verenigingen en Stichtingen, december 1961 E 635.451: E 741.23

\section{LEER VAN DE CONTROLE}

\section{Steekproeven als middel van accountantscontrole}

$\mathrm{H}$ e e $\mathrm{r}$ de $\mathrm{n}, \mathrm{A}$. v a $\mathrm{n}-\mathrm{Na}$ een korte beschouwing van de na-oorlogse literatuur waarin de steekproef als middel van accountantscontrole stelselmatig wordt onderzocht, volgt een beknopte uiteenzetting van de stratificatie-methode. Bij deze methode wordt voor een reeks posten de steekproefomvang bepaald, uitgaande van een fout-tolerantie, uitgedrukt als percentage van het totaalbedrag, en een bepaald toegelaten risico. Het voordeel is dat bij een voldoend aantal grootte-klassen het aantal posten in de steekproef beperkt is. Een be$z w a a r$ is de voorbereiding welke deze methode vereist. Mede teneinde dit bezwaar te ont- 
gaan heeft de auteur een nieuwe steekproefmethode ontworpen genaamd de ,guldenrangnummermethode". Hierbij wordt de wijze waarop een te controleren postenreeks zich in feite manifesteert geheel losgelaten en (in gedachten) getransformeerd in een reeks guldens. Aan elke gulden in deze reeks wordt een eigen rangnummer gegeven. De methode wordt uitvoerig beschreven waarbij naar voren komt dat zij meerdere bijkomende voordelen biedt. Als grootste voordeel wordt vermeld dat met deze methode de grens van eenvoud in voorschrift en minimale omvang van de steekproef wordt bereikt.

De omvang van de steekproef hangt af van de tolerantie en het toegelaten risico. Teneinde tot een bedrijfseconomisch verantwoorde controleomvang te komen worden nut en kosten van de controle tegen elkaar afgewogen. Uitgaande van een tweetal premisses omtrent het nut van controle kan de maximale steekproefomvang in een eenvoudige formule worden uitgedrukt.

Voorts wordt nader ingegaan op het verband tussen steekproefomvang en interne controle en op de plaats van de steekproef in de controleleer.
A IV - 3
Maandblad voor accountancy en bedrïfshuishoudkunde, december 1961
E $635.451:$ E $741.23:$ E 76

\section{Bewusste Auswahl oder Zufallsauswahl bei der aktienrechtlichen Pflichtprüfung?}

B u chner, R. - In Duitsland maakt de accountant bij zijn controlewerkzaamheden gebruik van gerichte steekproeven. De keuze van de te controleren posten kan zijn gericht op bijzondere gevallen dan wel betrekking hebben op de grootre van de posten. Tot de bijzondere gevallen kunnen bijvoorbeeld die worden gerekend, welke zich voordoen in de laatste weken voor het afsluiten van de boeken. Een gevaar van de methode van de bijzondere gevallen is dat niet zeker is of gevallen welke op grond van ervaring als bijzonder gelden, ook bijzonder blijven. Wordr de keuze van de posten gedaan op basis van de grootte van de te controleren post dan blijft het gevaar bestaan, dat onjuistheden bij kleine posten, welke voor de oordeelsvorming van de accountant van belang kunnen zijn, niet worden ontdekt. In de vakliteratuur wordt met betrekking tot de gerichte steekproef vooral ingegaan op het probleem van de grootte van de steekproef. Ofschoon de keuze van de grootte aan de accountant wordt overgelaten worden factoren genoemd welke de omvang der steekproef in positieve of negatieve zin beïnvloeden. De auteur vermeldt een aantal van deze factoren en wijdt voorts, onder verwijzing naar de Amerikaanse literatuur, aandacht aan de toepassing van de willekeurige steekproef bij controlewerkzaamheden. Deze steekproeven hebben in Duitsland naar zijn mening nog niet voldoende aandacht verkregen.

A IV -3

E $635.451:$ E $741.23:$ E 76

Die Wirtschaftsprüfung, december 1961

\section{B. BEDRIJFSHUISHOUDKUNDE}

\section{a. ALGEMENE BEDRIJFSHUISHOUDKUNDE}

\section{WAARNEMINGSMIDDELEN}

\section{Operations Research}

In het repertorium van februari 1962 werd het Operations-Researchnummer van Industrielle Organisation, 1961, nr. 11 besproken. Behalve enige losse bijdragen bevatte dit nummer enige lezingen van de vergadering van de Sweizerische Vereinigung für Operations Research. Nu verschenen in nr. 12 van 1961 en nr. 1 van 1962 de overige lezingen. Deze nummers bevatten de volgende bijdragen: Eduard Stiefel „Entwicklung der mathematischen Methoden zur Lösung von Extremalproblemen”, Antoine J. Guisolan "Travaux de planification militaire et recherche opérationelle”, Wilhelm Krelle „Optimale Entscheidungen bei Unsicherheit”, Enst Billeter "Wesen und Anwendungsmöglichkeiten des Operations Research", Rudolf Henn "Wirtschaftliche Anwendungsmöglichkeiten Stochastischer Prozesse", Charles Salzmann "Simulation du processus de production d'une importance aciérie intégrée" en E. M. L. Beale "Some Uses of Computors in Operational Research".

$\mathrm{Ba}$ III-2 Industrielle Organisation, 1961, nr. 12; 1962, nr. 1

E 76

\section{LEER VAN DE KOSTPRIJS EN DE PRIJSVORMING}

\section{Direct costing and its significance in marketing}

$S \mathrm{~m}$ it $t$ e $n, L$. J. - Een van de meest algemeen aanvaarde drogredenen van het moderne bedrijfsleven is, dat de directie beslissingen kan nemen aan de hand van een kostprijs, die gebaseerd is op de integrale kosten. Voor doelmatige beslissingen is kennis van de marginale 
winst vereist; dit noemt de schrijver "contribution"-marge, zijnde de marginale opbrengst na aftrek van de marginale variable kosten. Voor ieder produkt moet per marktsector worden berekend de contribution-marge en de kosten, die uit deze marge moeten worden gedekt. Van de contribution-marge worden de verkoopkosten afgetrokken en dan resteert de ,net area contribution". Dit gegeven wordt gebruikt om de relatieve winstgevendheid van de verschillende marktsectoren te beoordelen en om de marktstrategie te bepalen.

Bij de kostenverbijzondering wil de schrijver onderscheid maken tussen kosten van het produkt en kosten van het bedrijf. Beide hebben vaste en variabele componenten. De bedrijfskosten zijn indirecte kosten ten opzichte van het produkt en directe ten opzichte van de organisatie. De bedrijfskosten mogen niet ten laste van het produkt gebracht worden, omdat anders de beslissingen, die in het bijzonder de organisatie of het produkt betreffen geen juiste basis hebben. Er is een school, die meent dat een produkt pas rendabel is als het een surplus boven het aandeel in de overhead levert. De schrijver is het hiermee niet eens.

$\mathrm{Ba}$ IV - 2

E 136.232

The Canadian Chartered Accountant, december 1961

\section{LEER VAN DE FINANCIERING}

\section{Het balansdelict in de openbaar gemaakte jaarrekening}

Ysselmuiden, Mr. Th. S. - Artikel 336 van het Wetboek van Strafrecht (Sr) keurt het openbaar maken van een onware jaarrekening strafwaardig. Volgens stemmen uit de praktijk is de wetgeving op vennootschapsgebied volkomen onvoldoende. De auteur gaat in dit artikel na of dit oordeel op de tekst van artikel $336 \mathrm{Sr}$ gegrond is. Hierbij wordt de methode van de rechtsvergelijking gevolgd en het terrein van onderzoek afgebakend tot de landen der Europese Economische Gemeenschap.

Allereerst wordt nagegaan of de wet het misdrijf volvoerd acht wanneer willens en wetens een onware voorstelling van vermogen en/of resultaat of een zodanige toelichting op de jaarrekening is gepubliceerd, of dat de wetgever in de delictomschrijving, behalve genoemde toeleg, een verder reikend oogmerk bij de dader vordert. Blijkens de rechtspraak in Frankrijk en Duitsland en de parlementaire historie in Nederland wordt publikatie van een valse balans in deze landen voetstoots straf waardig geacht.

Volgens de nieuwe opvattingen in Frankrijk en Italië is het vormen van stille of geheime reserves in beginsel strafbaar. De auteur is van oordeel dat vanuit strafrechtelijk oogpunt beschouwd er weinig grond is voor het in Nederland gehuldigde onderscheid: onzichtbaar vormen van reserves is niet, onzichtbaar opheffen wcl laakbaar. In de tekst van artikel $336 \mathrm{Sr}$ wordt de samenhang van balans en resultatenrekening onomwonden tot uitdrukking gebracht. Die samenhang verbiedt een ongunstige gang van zaken te verbloemen evengoed als een voorspoedige te verduisteren. Ter beantwoording van de vraag of die feiten allén de strafsanctie wettigen is mede van belang de omstandigheid of de onware voorstelling van de realiteit gevolg is van opzettelijk onjuist waarderen of van een wijziging van de standaard waarin de bezittingen zijn uitgedrukt. De balans op basis van de vervangingswaarde is hier te lande nog volstrekt niet in goed koopmansgebruik geworteld. De overtreding van een norm die zo weinig in het rechtsbewustzijn leeft, kan niet strafwaardig zijn zolang zij niet in een wettelijke bepaling is vastgesteld. In Frankrijk daarentegen heeft - langs fiscaalrechtelijke weg - de vervangingswaardebalans zo goed als algemeen ingang gekregen.

De eigen strafrechtssfeer stelt aan vervolging een dubbele eis. Alleen op zo ernstige vergrijpen als die, welke de rechtsorde zelf aantasten, verdient straf te staan. Ook moet de bestraffing het gemene welzijn baten. Ten aanzien van de eerste eis is de auteur van oordecl dat de belangen, welke thans met de grotere onderneming verbonden zijn toetsing vragen van het balanswaarheidsgebod en wel blindelings. Afwijking zowel ten ongunste als ten gunste van de werkelijkheid zal het recht hebben te keren.

$\mathrm{Ba} \mathrm{V}-1$

Nederlands Juristenblad, 7 oktober 1961

E 771

\section{De belegger en de concentratie in het bedrijfsleven}

Posthum us M e y es, W. C. - Indien maar even verondersteld wordt, dat een bepaalde vennootschap voor overname in aanmerking komt stijgt de koers van de aandelen van deze vennootschap, hetgeen soms de biedende partij van het bod doet afzien omdat de koers steeg boven de koers die hij maximaal bereid is te betalen. De schrijver stelt in verband hiermede, dat besturen van vennootschappen, die in principe besluiten tot fusie over te gaan, aan de Vereeniging voor den Effectenhandel moeten verzoeken de notering van hun fondsen te staken, ter voorkoming van misbruik van voorwetenschap. De schrijver 
betreurt het, dat in de berichtgeving over de fusie zo weinig wordt verteld over de aspecten die aan de fusie verbonden zijn, zoals het laten afvloeien van personeel, het uitkopen van commissarissen, e.d. Ergerlijk is het indien de directie van een onderneming, die onverwacht een bod ontvangt de aandeelhouders adviseert niet op het aanbod in te gaan, omdat zij de geboden prijs te laag acht. Een bestuur geeft met een dergelijke uitlating toe, dat zij jarenlang de aandeelhouders onvoldoende heeft ingelicht omtrent de waarde van hun bezit. Buitengewoon te waarderen valt het indien, zoals helaas slechts bij hoge uitzondering voorkomt, de aandeelhouders van de vennootschap waarop een bod is uitgebracht, door het bestuur in een buitengewone vergadering worden bijeengeroepen.

De vele fusies van de laatste jaren hadden meestal een gunstige invloed op de beurskoers. Wordt een bod in contanten uitgebracht, dan houdt dit in dat liquiditeiten van de N.V., welke het bod doet, in handen van beleggers komen. Geschiedt de betaling in de vorm van aandelen der overnemende N.V., dan komt daar feitelijk altijd toch weer een deeI van op de markt. Vormen twee vennootschappen tezamen een nieuwe N.V. dan kan ook dit de handel verlevendigen, o.a. omdat de aandelen van de bcide vennootschappen, die vroeger elk op zich wellicht een vrij kleine markt hadden, nu op een ruime markt kunnen rekenen.

$\mathrm{Ba} \mathrm{V}-3 \mathrm{~b} \quad T$ ijdschrift voor Vennootschappen, Verenigingen en Stichtingen, november 1961

E 325.232

\section{LEER VAN DE ORGANISATIE}

\section{Spaltungstheorie contra wet en verdrag}

L u y k e n, M r. H. - Naar aanleiding van het tussen Nederland en de Duitse Bondsrepubliek gesloten Algemeen Verdrag, waarvan o.a. het Financieel Verdrag deel uitmaakt, bespreekt de schrijver de pogingen van Duitse zijde om de z.g. Spaltungstheorie op buitenlandse rechtspersonen toe te passen. Gesteld wordt nl. dat een Nederlandse vennootschap in Duitsland ongewijzigd voortbestaat met de oude Duitse aandeelhouders; aan deze "Spalt-vennootschap" komt het in Duitsland liggende vermogen toe. De Nederlandse Staat zou dus nict kunnen beschikken over de in Duitsland gelegen aandeelhoudersrechten in Nederlandse vennootschappen, terwijl zulks krachtens het Besluit Vijandelijk Vermogen is geschied.

De schrijver acht deze toepassing niet geoorloofd; aan de hand van geallieerde naastingsmaatregelen, vastgelegd in wet en verdrag, wordt aangetoond dat een dergelijke splitsing der aandeelhoudersrechten in een binnen- en buitenlands gelokaliseerd deel niet baat, indien de naasting beide delen betreft en zowel voor binnenland als buitenland bij verdrag erkend is, zoals in casu is gebeurd.

Gezien de rechtspraak van het Bundesgerichtshof en de toelichting van de Bondsregering bij het Algemeen Verdrag, acht de schrijver het nodig dit verdrag, hoewel volkomen duidelijk, aan te vullen opdat niet getornd kan worden aan het vermogen van Nederlandse rechtspersonen in Duitsland.

In cen naschrift wijst de schrijver op een Duits artikel van hoge ambtelijke zijde waarin zijn opvatting wordt bevestigd, hoewel ook deze schrijver in bepaalde gevallen, maar ten onrechte, aan het bezettingsrecht schijnt te willen tornen.

De redactie van dit repertorium wijst erop, dat volgens bet Algemeen Handelsblad van 14 maart 1962, met West-Duitsland een Zusatzabkommen zal worden gesloten, waarbij zal worden bepaald, dat de Spaltungstheorie niet van toepassing zal zijn op de vermogens van Nederlandse vennootschappen in West-Duitsland.

$\mathrm{Ba}$ VI - 1

De Naamlooze Vennootschap, december 1961

E 432

\section{Fusie}

Het novembernummer 1961 van het Tijdschrift voor Vennootschappen, Verenigingen en Stichtingen is geheel gewijd aan de fusie van ondernemingen. Het bevat een bijdrage van Prof. J. Brands over "Concentratie van ondernemingen", waarin deze uitgebreid ingaat op de visie van Dr. P. Rijkens. Prof. Dr. C. F. Scheffer bespreekt de financiële aspecten van de concentratie. Drs. W. Hessel behandelt de gevolgen voor de werknemers en bepleit meer medezeggenschap van de werknemers bij beslissingen over fusie, reorganisatie e.d. Mr. H. Luyk belicht de "Organisatorische aspecten van de fusie”. De civielrechtelijke zijde van het vraagstuk wordt belicht door Mr. Dr. H. F. A. Völlmar, die ook de regeling van de fusie in het nieuwe Burgerlijk Wetboek vermeldt. A. J. H. van Velzen behandelt de concentratietendenzen in de middenstand, terwijl Drs. G. M. C. Panhuysen een overzicht 
geeft van een aantal belangrijke fusies van open N.V.'s na 1945, met een korte omschrijving. van de motivering. De bijdragen van W. C. Posthumus Meyjes en Prof. Dr. J. Waterink zullen elders in dit repertorium afzonderlijk worden besproken.

$\mathrm{Ba}$ VI - 5 Tüdschrift voor Vennootschappen, Verenigingen en Stichtingen, november 1961

E 633.11

\section{Psychologie en concentratie van ondernemingen}

W a t e r in k, Prof. D r. J. - De concentratie van bedrijven heef $\mathrm{t}$ onderscheiden psychologische aspecten. Het bereid-zijn om over concentratie te denken is op zichzelf reeds een belangrijk psychologisch gebeuren, omdat het een groot verschil is of wij spreken over concentratie van bedrijven, die tot stand komt met het oog op een betere ontplooiingsmogelijkheid in de verre toekomst, dan wel of men over concentratie spreekt omdat men nu reeds het gevoel heeft, dat het eigen bedrijf stroef loopt of bedreigd wordt. Een ander aspect waarbij psychologische factoren een rol spelen is de zogenaamde objectieve waardebepaling van het bedrijf en de aandelen: Een jonge directeur, die 10\% van de aandelen bezit en vervuld is van plannen voor vernieuwing en expansie zal minder geneigd zijn op een aanbod tot overname in te gaan dan een oudere directeur, die $30 \%$ van de aandelen bezit, op het punt staat af te treden en het gevoel heeft, dat het succes van de onderneming in het verleden eigenlijk alleen van hem afhankelijk is geweest. Tijdens een discussie tussen deze twee directeuren zullen zij niet vlug hun eigenlijke argumenten openlijk naar voren brengen, terwijl het juist deze zijn die tijdens de discussie hoe langer hoe zwaarder accent krijgen. Steeds komt bij concentratie van ondernemingen het persoonsbelang sterk naar voren. Hieronder verstaat de schrijver datgene, dat niet in geld is uit te drukken maar dat de mens een gevoel geeft van waarde-in-zichzelf, het gevoel dat zijn persoon tot gelding komt. $\mathrm{Ba}$ VI - 5 Tijdschrift voor Vennootschappen, Verenigingen en Stichtingen, november 1961 E 633.11

\section{Some aspects of controllership}

Robinson, J. R. - In dit artikel wordt een aantal punten aangeroerd welke de auteur van bijzonder belang acht voor de functie van de controller in het grote bedrijf. In de eerste plaats noemt de auteur de "cost control", waarmede wordt bedoeld het vaststellen van de te volgen beginselen van de kostenberekening, het analyseren van de "resultaten" en het zoeken naar middelen om de kosten te verlagen. Deze zaak dient in handen te worden gelegd van een topf unctionaris van het bedrijf en mag niet worden toevertrouwd aan de uitvoerende afdelingen. Indien een bedrijf een hoge mate van efficiëntie wil bereiken, zal het systeem van kostenbepaling de volgende vier kenmerken moeten vertonen: (1) het vaststellen van een maandbudget, bij voorkeur op basis van standaardhoeveelheden en standaardprijzen. (2) het berekenen van de kosten per kostenplaats (centrum van verantwoordelijkheid), (3) de kostenbepaling ten dienste van de kostenbewaking moet zich beperken tot de directe of marginale kosten, (4) de kostenberekening dient meer tot in details te gaan, naarmate deze de eigenlijke technische uitvoering nadert. Een tweede belangrijk aspect van de functie van de controller wordt gevormd door de planning op lange termijn; hiermede bedoelt de auteur de projectie van de financiële positie en de winstgevendheid van het bedrijf over 5,10 of 15 jaar. Deze is noodzakelijk teneinde antwoord te kunnen geven op vragen betreffende het entameren van een bedrijfspolitiek gericht op verruiming van bestaande markten, het penetreren van nieuwe markten, het lanceren van nieuwe produkten e.d. De planning op lange termijn vereist een coördinator die een grondige kennis bezit omtrent de verschillende onderdelen van het bedrijf. Dit geldt evenzeer voor een volgend punt, nl. dat van de budgettering. Daarnaast vestigt de auteur er de aandacht op dat de controller volledig op de hoogte dient te zijn van het financiële beheer en de belastingen. Ook tot de „operational research" kan de controller een bijdrage leveren.

$\mathrm{Ba}$ VI - 16

The Internal Auditor, Fall 1961

E 642.22

\section{LEER VAN DE ARBEIDSVOORWAARDEN}

Wettelijke aansprakelijkheid voor de werkgever

E y k, M r. N. W. A. v a n - Volgens art. 1403, 3e lid van het Burgerlijk Werboek is de werkgever verantwoordelijk voor de schade die zijn werknemers veroorzaken terwijl zij in zijn dienst zijn. Bovendien volgt uit het $5 \mathrm{e}$ lid van dit artikel dat de werkgever verantwoordelijk blijft, ook al kan hij aantonen dat hij de daad niet heeft kunnen beletten.

Voor de verantwoordelijkheid geldt dat er een direct verband met de opgedragen werkzaamheden dient te zijn; hoewel het reizen tussen huis en werk niet als zodanig wordt beschouwd, wijst de schrijver op enkele vergaande arresten van de Hoge Raad inzake aard en 
duur van dit directe verband met het werk, met name ten aanzien van ambulant personeel zonder vaste werktijden, zoals bijvoorbeeld reizigers.

Hoewel krachtens art. 1401 en 1402 B.W. de verantwoordelijkheid van de werknemer zelf onverminderd blijft bestaan en deze dus eveneens aansprakelijk gesteld kan worden, acht de schrijver een afdoende verzekering tegen deze vergaande aansprakelijkheid van de werkgever geboden.

Ba VII - 1

E 641.21

Gids voor Personeelsbeleid, Arbeidsvraagstukken, Sociale Verzekering, december 1961

\section{A system of governmental wage control; experience of the Netherlands, 1945-60}

B h a t i a, R a $t$ t a n J., en A rie C. B o u t e $r-$ De auteurs beschrijven de loonvorming in Nederland na 1945 en geven daarna een kritische beoordeling aan de hand van de volgende twee criteria: het land moest voldoende exporteren en voldoende besparingen opbrengen om zijn investeringsbehoeften te bevredigen.

$\mathrm{Ba}$ VII- 3

International Monetary Fund, Staff Papers, december 1961

E 225.4

Het N.V.-recht en de zelfstandigheid van de ondernemer

Ove n, Prof. Mr. A. van - Het artikel van Prof. van Oven is geschreven naar aanleiding van het door de Wiardi Beckman Stichting in 1959 gepubliceerde rapport geriteld: „De hervorming van de onderneming”.

Het rapport geeft als motief: ,het recht heeft dienstbaar te zijn aan de verwerkelijking van rechtsopvattingen die in het maatschappelijk bewustzijn zijn gegroeid". De schrijver twijfelt eraan of op de conclusies van het rapport dit motief inderdaad van toepassing kan zijn. De voorgestelde democratisering beantwoordt volgens de schrijver niet aan de in het maatschappelijk bewustzijn gegroeide rechtsopvattingen, omdat het voorstel - om aan bestuur en aandeelhoudersvergadering een aantal thans voor de functie van deze organen essentiële bevoegdheden te ontnemen en deze over te brengen naar de raad van commissarissen, waarvan de meerderheid door anderen dan de aandeelhoudersvergadering is aangewezen - via de omweg van hervorming van het N.V.-recht in wezen een einde maakt aan de ondernemerszelfstandigheid. Het heeft volgens Prof. van Oven bovendien geen zin te trachten door hervorming van het N.V.-recht een aanzienlijke machtsverschuiving te bewerkstelligen. Machtsverhoudingen zijn niet zozeer door het N.V.-recht gecreëerd, maar zijn meer een noodzakelijk gevolg van het bestaan ener grote, door velen gefinancierde onderneming.

Wat de controle op de juistheid en volledigheid der verslaggeving betreft, constateert Prof. van Oven, dat deze in de huidige wet zeer onvoldoende is geregeld. Maar de in het rapport voorgestelde vennootschapskamer wijst hij af zolang niet is gebleken, dat hetzelfde resultaat door controle van onafhankelijke accountantskantoren bereikt kan worden.

$\mathrm{Ba}$ VII -4

E 641.216 .2

De Economist, december 1961

\section{Vrij verkeer van werknemers binnen de Europese Gemeenschap}

Grevenstein, Mr. J. A. U. M. va n - Met ingang van 1 september 1961 trad een verordening in werking betreffende de eerste maatregelen ter verwezenlijking van het vrij verkeer van werknemers binnen de E.E.G. In deze verordening, welke gedurende twee jaar van kracht zal zijn, wordt het vrije verkeer nog beperkt door de aan de nationale arbeidsmarkt verleende voorrang. Alleen indien op de normale arbeidsmarkt van het eigen land geen geschikte arbeidskrache aanwezig is, hebben vreemde werknemers recht op een ter zake strekkende werkvergunning. Op deze regel gelden enkele uitzonderingen, zoals in het geval dat zich kennelijke tekorten voordoen en bij aanbiedingen van bijzondere aard (gespecialiseerde beroepen, e.d.). Inzake de verlenging van de tewerkstelling blijkt de voorrang van de nationale arbeidsmarkt reeds aanzienlijk beperkt.

Een der voornaamste hindernissen bij de totstandkoming van de verordening betrof de voorrang van de arbeidsmarkt van de E.E.G. ten opzichte van derde landen (Spanje, Griekenland, e.a.). De grote tegenstellingen tussen Italie als voor- en Duitsland als tegenstander van deze voorrangsregel leidden tenslotte tot een weinig geslaagd compromis.

De schrijver behandelt tenslotte de wijze waarop het tot elkaar brengen en het compenseren van aanbiedingen van en aanvragen om werk kan worden bevorderd; de bestaande arbeidsbureaus hebben hier de voornaamste taak. Gewezen wordt nog op instelling van onder andere een Raadgevend Comité waarin de regering en de verenigingen van werknemers en werkgevers van elk der lid-staten zijn vertegen woordigd.

$\mathrm{Ba}$ VII - 10

Sociaal Maandblad Arbeid, 25 november 1961

E 433.421

m a b blz. 180 